\title{
Life History Predicts Perceptions of Procedural Justice and Crime Reporting Intentions
}

\author{
Daniel J. Kruger ${ }^{1}$ • Joseph L. Nedelec ${ }^{2}$ Thomas M. Reischl ${ }^{1} \cdot$ Marc A. Zimmerman $^{1}$
}

Published online: 28 May 2015

(C) Springer International Publishing 2015

\begin{abstract}
Evolutionary life history theory (LHT) is a powerful organizing framework central to the life sciences. Interest in biosocial criminology is growing, and adoption of LHT may accelerate progress toward an integrative evolutionarily informed human science. We examined the relationship of life history to attitudes toward the police using data from a demographically representative community-wide survey in a Midwestern county with an urban center exhibiting high rates of violent crimes. As expected, life history was associated with demographic characteristics. Controlling for demographics, slower life history was associated with greater perceptions of procedural justice and police legitimacy, i.e., intentions to contact the police. LHT may promote an integrative human science and a deep theoretical framework for understanding modern social patterns.
\end{abstract}

Keywords Life history $\cdot$ Procedural justice .

Police legitimacy $\cdot$ Biosocial criminology

Examinations of the role of police in societies and the purpose of the institution of law enforcement have been a consistent component of the social science literature since at least the formation of the earliest formal police force in the 19th century. These examinations often center on the manner in which the police are employed to maintain social order as agents of larger societal authorities. Until recently, scholars have left relatively

This project was supported by grants 1U48DP001901-01 and 1U01CE001957-01 from the Centers for Disease Control and Prevention.

Daniel J. Kruger

kruger@umich.edu

1 School of Public Health, University of Michigan, 1420 Washington Heights, Ann Arbor, MI 48109-2029, USA

2 University of Cincinnati, Cincinnati, OH, USA unaddressed the ways in which the police can have influence as agents within the individual social networks of citizens in a community or neighborhood. Elemental to comprehending how the police can affect the social relationships and wellbeing of group members within a social network is the way in which the public view the police (Tyler 1997).

Given the influential role police can play in social networks, understanding public perceptions of the police has substantial academic and practical value. Examinations of this topic can help illuminate important theoretical issues regarding justice as well as guide policy directed at the behaviors and functioning of law enforcement agencies (Lai and Zhao 2010). This recognition has manifested in the extant literature where considerable empirical and theoretical attention has been paid to public perceptions of police over the past few decades. Assessments of the relationship between public opinion of the police and various outcomes have shown that more positive attitudes toward and a greater willingness to contact the police appear to be associated with increased cooperation with the police (Tyler 2004), law-abiding behavior (Sunshine and Tyler 2003; Tyler 2006), and greater probability of adherence to the philosophy of important policy initiatives like community policing (Posick et al. 2013). The bulk of the literature in this area traces its origin to Tyler's $(1997,2004$, 2006) process-based model of policing. Tyler's model is a social-psychological framework for assessing the intricacies underlying police-citizen relations and focuses on the concepts of procedural justice and police legitimacy (Reisig et al. 2007; Tyler and Wakslak 2004). The model maintains that police can increase public perception and willingness to interact with police by allowing for the expression of opinion by members of the public, by interacting with the public in a respectful manner, and by clearly explaining the rationale for their law enforcement decision making (Tyler 1997, 2004, 2006; Tyler and Wakslak 2004; Gibson et al. 2009). Collectively, these socially interactive techniques, it is argued, serve to heighten the fairness (aka, procedural justice) and 
legitimacy with which the public views the police. Literature assessing the process-based model has provided empirical support for the association between attitudes toward police and various behavioral and procedural outcomes (Reisig et al. 2007; Sunshine and Tyler 2003; Tyler 2006; Tyler and Wakslak 2004).

Although the literature examining the process-based model of policing has evaluated the relationships between attitudes and various outcomes, there has also been a great deal of attention paid to the antecedents of the observed group and community differences in terms of perceptions of the police and reporting behaviors and intentions (Wolfe 2011). The majority of these analyses have focused on a number of basic demographic factors such as race and ethnicity (Lai and Zhao 2010; Posick et al. 2013; Tuch and Weitzer 1997; Tyler 2005), age (Goudriaan and Nieuwbeerta 2007; Lee et al. 2010), sex (Baker et al. 2014), and education (Lai and Zhao 2010).

Despite the substantial attention paid to these demographic characteristics, few consistent findings have arisen beyond the differences in public perception of the police between racial groups (Brown and Benedict 2002; Lai and Zhao 2010). Indeed, researchers in this area have noted that demographic characteristics may be insufficient to explain the variance in attitudes toward police and have called for a more nuanced approach (Lai and Zhao 2010). As part of this nuanced approach, researchers have recognized that there are currently multiple theoretical viewpoints regarding the antecedent variables influencing perceptions of the police, complicating explanations of the observed variance in perceptions of and willingness to contact the police (Gibson et al. 2009; Lai and Zhao 2010). Additionally, other scholars have noted that some research examining potential influential factors on the variance in perceptions of police is atheoretical and therefore lacking in guidance in terms of the production of hypotheses (Brown and Benedict 2002). Furthermore, embedded in this area of research is the recognition that perceptions of the police are inexorably enmeshed with views regarding the role and purpose of police within a social milieu (Brown and Benedict 2002; Tyler 1997). In other words, the manner in which citizens view the police based on issues such as legitimacy and procedural justice is based partially on their view of the police as social actors within the wider community. Thus, the police can be considered as integral components of individuals' social networks that can potentially have an impact on one's fitness-relevant experiences.

Although the majority of criminological analyses (including those examining attitudes toward police) are based on sociological theories and methodologies, a growing minority of criminologists are diverting from this practice by employing the methods of fields outside of criminology (Walsh and Beaver 2009). This perspective, known as biosocial criminology, is based on the assumptions and methodologies of fields such as behavioral genetics, neuroscience, molecular genetics, and evolutionary biology (Beaver 2009). At its core, biosocial criminology recognizes that all phenotypic development and expression are the results of an interaction between genetic/biological processes and environmental factors, rather than being solely determined by either component (Walsh and Beaver 2009). However, the interaction is not equally weighted across phenotypic variance, and genetic and nongenetic factors differentially contribute to variance across phenotypes (see Barnes et al. 2014a and Wright et al. 2015). Importantly, this dynamic applies to the processes that influence social-psychological attitudes as well as those which influence morphological traits (Walsh and Beaver 2009). To date, biosocial criminologists have assessed a number of traditional criminological assumptions and have convincingly illustrated that adherence to a purely sociological examination of crime, criminality, and criminal justice system processing produces an incomplete understanding of these topics (Barnes et al. 2014b; Beaver 2009; Beaver et al. 2013a; Walsh and Beaver 2009; for reviews, see Moffitt 2005; Moffitt et al. 2011; Raine 2002). One component of a biosocial criminology approach is derived from evolutionary biology and is known as life history theory (LHT). Although some researchers have employed LHT in empirical assessments of criminality (e.g., Boutwell et al. 2013; Nedelec and Beaver 2012; Wilson and Daly 1997), devoid from the criminological literature is an application of LHT to an examination of attitudes toward police.

The current study seeks to address this gap and employs a novel approach by integrating LHT into the analysis of public perceptions of the police. More specifically, we examine how an individual's life history can shape trust in the police and intention to contact or interact with police beyond the influence of various demographic factors. In doing so, we illustrate how life history theory may provide the theoretical scaffolding for which to assess the antecedent influences on attitudes toward the police and willingness to contact the police.

\section{Life History Theory}

Evolutionary LHT is a powerful framework for understanding behavioral and physiological strategies, including effort tradeoffs across the lifespan (Gadgil and Bossert 1970), as functional adaptations to environmental conditions designed to maximize average lifetime inclusive fitness (Roff 1992; Stearns 1992). Fisher (1958) stated the importance of understanding the physiological mechanisms that regulate the balance of investments between reproduction and maintenance of the body, as well as the life history and environmental factors that would affect the relative allocations. Cole's (1954) paper addressing the simultaneous existence of semelparity and iteroparity brought increasing attention to the study of life cycle traits and their variations. 
Schmalhausen (1949, as cited in Dobzhansky 1950) noted that unpredictable extrinsic mortality accelerates development and reproduction, leading to higher fertility. The future predictability of those resources most needed for reproduction will shape an organism's life history (Weinrich 1977). Species living in environments with resource instability and unpredictability of future events (due to high predation rates, for example) will tend to evolve clusters of traits associated with rapid and prolific breeding with relatively low investment in offspring (MacArthur and Wilson 1967; Pianka 1970). Species living in stable and predictable environments instead have longer-term, "slower," strategies of investing more so in somatic and parental effort with lower reproductive rates and longer intergenerational times than those in less predictable environments. In addition to life history variation between species, there are individual differences in strategies within species, which is partially contingent upon environmental conditions (Rushton 1985).

Because the total amount of effort is limited, organisms face tradeoffs between different possible forms of investment. These inherent tradeoffs include somatic versus reproductive effort, mating versus parental effort, current versus future reproduction, and quantity versus quality of offspring (Roff 1992; Stearns 1992). In the early stages of an organisms' life, the somatic effort of building and maintaining one's body takes precedence over reproduction. Once an organism reaches sexual maturity, however, a greater portion of the organisms' resources becomes devoted to reproduction. For some species, reproductive effort is predominantly mating effort; however, many animal species also exhibit parental care of offspring.

\section{Human Life History}

Humans have exceptionally long life spans, substantially longer developmental periods, extended juvenile dependence, relatively stable reproductive pair bonding, and high levels of paternal investment compared to closely related species (Kaplan 1997; Low 1998). The longer developmental period is attributed to the very large somatic investment in human brain development (Barton and Capellini 2011) and the ecological dominance attained by our hominid ancestors (Alexander 1979), which reduced predation pressure.

Although paternal investment is relatively high on average, male mating effort remains substantial. The shift in the male allocation of effort from somatic to mating to parenting over the life course helps explain the pattern of risky behavior underlying the peak in sex differences in mortality from behavioral causes during young adulthood (Kruger and Nesse 2006). The observed peak of risky behaviors in young adulthood corresponds with entrance into mating competition. Consequently, the risky behavioral strategies of young males (compared to females) were selected for over time because they tended to aid in mating competition (Wilson and Daly 1992). Humans also have a substantial postreproductive life span, which may increase inclusive fitness (Hamilton 1966) through the alloparenting of extended family members including grandchildren (Hrdy 2009) as well as the transfer of skills and knowledge to subsequent generations (Lee 1997).

\section{Human Life History Variation}

Initially, life history variation was examined exclusively between species (Figueredo et al. 2005). Rushton (1985) proposed that LHT could be useful in understanding human individual differences in behavioral strategies and physiological functioning. Although life history strategies are partially heritable (Figueredo and Rushton 2009; Figueredo et al. 2004; Heath and Hadley 1998; Minkov and Bond 2015), human life history strategies are influenced by environmental circumstances such as socioeconomic and cultural conditions and physical constraints (Heath and Hadley 1998). Thus, LHT can be used as a framework for understanding variation in human physiological and behavioral strategies as evolved adaptations to socioenvironmental conditions. For example, Quinlan (2007) found lower levels of parental investment in environments where parenting cannot improve offspring survival due to high pathogen load. Additionally, women who grow up without father involvement show earlier sexual activity, as well as a lack of interest or ability to form and/or maintain long-term monogamous relationships (Belsky et al. 1991; Chisholm 1999). Likewise, women experiencing a warm and highly investing father reach menarche later than do women with an emotionally distant or absent father (Ellis et al. 1999). The relationship between parental separation and reproductive pattern is partially mediated through variation in androgen receptor genes; however, this does not completely account for the effects of father absence (Comings et al. 2002). Each of these empirical observations illustrates the manner in which environmental cues can influence individuals' life history strategies.

The person-environment interaction underlying life history strategies can also shed light on the etiology of risky behaviors. For example, the discounting of future outcomes by many adolescents and young adults could be a rational response to uncertainty and would be exacerbated when uncertainty is relatively higher (Wilson and Daly 1997). Individuals who develop in relatively uncertain environments develop riskier behavioral strategies to take advantage of possibly fleeting opportunities (Chisholm 1999). Those living in chronically risky and uncertain environments (e.g., one with significant family conflict) are more likely to experience earlier menarche, earlier ages of reproduction, and higher reproductive rates (Chisholm 1999; Kim et al. 1997). Risky behaviors may have facilitated early reproduction before death occurs. As an illustration, community college students who had shorter lifespan estimates and 
higher estimates of the unpredictability of the future had a higher frequency of risk-taking (Hill et al. 1997). Employing data from the nationally representative Add Health study, Nedelec and Beaver (2012) illustrated that those respondents who had a more pessimistic future outlook (e.g., more likely to be killed by age 21) were also more likely to engage in juvenile delinquency and adult criminal behavior. Additionally, the authors found that pessimism about the future was also associated with an increased amount of sexual activity and number of lifetime sexual partners. Interestingly, these results were obtained for both males and females (Nedelec and Beaver 2012). At a macro level, Wilson and Daly (1997) found that neighborhood life expectancy (at birth) and neighborhood income inequality predicted neighborhood homicide rates across 77 neighborhoods within Chicago over a 5-year period. More specifically, the authors observed that for both males and females, shorter life expectancy at birth predicted higher homicide rates as well as overall mortality rates. Consequently, members of these high-mortality and unpredictable environments engaged in an increased amount of risky behavior (homicide). A less risky, long-term strategy was displayed in neighborhoods characterized by low mortality rates and predictable social environmental conditions.

\section{Human Life History Variation and Evolutionary Psychology}

Life history research in other species assesses the relationship between environmental conditions, behavioral and life event patterns, independent of any cognitive mediation. For humans, psychological measures bring the added value of identifying proximal mental processes or mechanisms that guide behavioral strategies (see Cosmides and Tooby 1994). Kaplan and Gangestad (2005) argue that an evolutionary psychology approach is crucial for an understanding of human life history variation and that LHT can effectively guide inquiry into the development, nature, and operation of psychological adaptations. To make optimal decisions in investment tradeoffs, organisms must assess relevant cues about the environment and integrate them. Kaplan and Gangestad (2005) noted that very little was known at the time about the adaptations by which organisms solve most tradeoff problems. Allocations and reallocations of effort typically involve both physiological and psychological processes, and such processes can and should be assessed.

Human psychometric assessments are complementary to the traditional biometric assessments of developmental parameters such as spacing of births, length of gestation, weight at birth, length of juvenile dependency, and age at sexual maturity. Although some may argue for the superiority of such "objective" life event data over self-reported psychological measures, the environmental mismatch between contemporary human populations and the environments in which their adaptations evolved creates difficulties for interpreting such measures (Figueredo et al. 2014). Contraception, scientific medicine and modern public health, industrialized food supplies and diverse and abundant diets, as well as many other cultural and technological innovations (including institutionalized law enforcement) have strong influences on the life events of people living in contemporary human societies. Thus, such outcome measures may not be indicative of evolved, and thus heritable, life history strategies. Psychometric assessments provide access to the functional and mediating processes for these distal achievements (Figueredo et al. 2014). Certain tradeoffs inherent in human life history, such as between investments in parental effort versus mating effort, also justify a psychometric approach (Kaplan and Gangestad 2005).

Figueredo and colleagues (see Figueredo et al. 2006) propose that a common factor underlies human life history parameters and reproductive, familial, and social behaviors. They proposed a continuum of strategies, called Differential K (see also Rushton 1985), ranging from a focus on short-term gains at the expense of long-term costs, high mating effort, and low parenting effort to long-term strategies, selective mating, and high parental effort. This continuum is related to impulsivity, social support, disregard for social rules, and risk-taking behaviors. Table 1 provides some examples of the variance in strategies along the Differential K continuum.

\section{Life History and Relations with the Police}

As noted above, no previous research has examined the relationship between life history and attitudes toward the police. Rushton (1985) predicted that individuals with slower life histories would have greater tendencies for following rules and laws, as mediated by higher intelligence, introversion, conscientiousness, and altruism. He noted the greater complexity of social organization in species with slower life histories, and that more complex social structures depended on individuals following social rules. Following this argument, Ellis (1988) proposed that victimful criminal offenses (property and especially violent crimes) are the opposite of altruism, and thus would be committed more often by those with fast life histories. Ellis (1988) reviewed nearly 500 studies and documented the association between serious criminal offenses and life history indicators such as the following: shorter gestation periods and lower birth weight, earlier sexual initiation, less stable pair-bonding, greater tendencies for extra-pair sexual relationships, lower parental investment in offspring, and shorter life expectancy. Empirical assessments of the association between attitudes and behaviors have shown that those who tend to follow rules and laws also have more favorable attitudes toward enforcers of such rules and laws (Sunshine and Tyler 2003; Tyler 2006). 
Table 1 Human life history variation (based on Ellis 1988; Pianka 1970; Rushton 1985)

Human life history

$\begin{array}{ccc}\text { Fast } & \text { Slow } \\ \text { Shorter } & \text { Gestation length } & \text { Longer } \\ \text { Shorter } & \text { Life expectancy } & \text { Longer } \\ \text { Short-term } & \text { Future outlook } & \text { Long-term } \\ \text { Rapid } & \text { Maturation rate } & \text { Slow } \\ \text { Early } & \text { Age of sexual reproduction } & \text { Delayed } \\ \text { High } & \text { Mating effort } & \text { Low } \\ \text { Many } & \text { Number of offspring } & \text { Few } \\ \text { Low } & \text { Parenting effort } & \text { High } \\ \text { High } & \text { Levels of risk-taking } & \text { Low } \\ \text { Low } & \text { Levels of altruism } & \text { High } \\ \text { Low } & \text { Degree of social organization } & \text { High }\end{array}$

There are additional reasons why individuals with slower life histories may have more favorable attitudes toward authorities than those with fast life histories. Slower life histories develop in environments where personal safety and access to resources are predictably reliable. Although competition for resources exists and may even be intense, the variation in outcomes is relatively low, and social status is based more so on potential for resource investment than on the outcomes of direct physical conflict. There are strong incentives for maintaining social stability: the preservation of resource holdings and to protect offspring and other kin, who are smaller in number, receive greater investment, and face lower extrinsic mortality risk. The returns gained from slow life histories lie more so in the future, and individuals may invest in behaviors and systems that help guarantee the attainment of those future outcomes. Thus, there is a convergence of interests with authority figures who enforce social norms and maintain continuity. This congruence may result in greater trust in police and stronger intentions to facilitate police work by reporting crimes and providing other information.

In contrast, those with faster life histories develop in environments where outcomes are less predictable, as variations in both mortality and reproductive success are substantially higher. Individuals, especially men, allocate substantially more energy to mating effort, including direct status competitions. The stability of social structure is lower, and individuals will rise and fall in social standings more rapidly than those in stable environments. Those in positions of authority, such as law enforcement officers, may be seen more so as successful competitors for social status and power within the social network, rather than being benevolent maintainers of a justified system. Thus, attitudes toward the police may be less favorable, relations more antagonistic, and cooperation in terms of reporting crimes lower.

\section{Hypotheses}

Based on the logic above, we hypothesize that slower life history will predict more favorable attitudes toward the police (i.e., greater trust and perceptions of fairness), greater intentions to contact the police to report a crime, and greater intentions to interact with police for any other reason than reporting a crime. In the vernacular of Tyler's process-based model, we 
expect that slow life history will have a positive relationship with measures of procedural justice, police legitimacy, and overall attitudes toward the police. Additionally, based on previous research (Gau et al. 2012; Tyler and Fagan 2008), we expect that more favorable attitudes toward the police (procedural justice) will predict intentions to interact with the police (police legitimacy), creating a mediated relationship with life history.

Congruent with existing life history research, we expect specific demographic characteristics to predict scores on life history measures. In technologically advanced nations, there is a transition from mating effort to parental investment and investment in extended kin across adulthood. Because of the large investment required for each of their offspring and lower potential reproductive capacity, women provide substantially greater parental investment than men do, whereas men expend comparatively more matting effort for obtaining partners (Trivers 1972). As a result, we expect that female respondents will report a slower life history strategy than their male counterparts. Higher educational attainment may be a product of slower life history, including longer time horizons for motivational outcomes, as well as an influence on behavior. Consequently, we expect educational attainment to be associated with a slower life history strategy. In terms of race, we expect that African Americans will be more likely to report fast life histories, as evidence illustrates their disproportionate likelihood of residing in dangerous and unpredictable neighborhoods (Anderson 1999). However, Dunkel (2012) found that hypothesized difference in life history strategy between Blacks and Whites were minimal.

We include these demographic characteristics in our model to provide a strong test of our central hypotheses. In order to test this hypothetical framework, we utilized data collected from a survey of respondents to a demographically representative countywide health survey in a community with an urban center known for high violent crime rates in the Midwestern United States. We created a path model analysis of our hypothetical framework, including demographic covariates.

\section{Method}

\section{Participants and Procedure}

Our study utilized data from the 2011 wave of a demographically representative countywide health survey in Genesee County, MI. Genesee County's urban center of Flint is an industrial city whose economy and population has followed the manufacturing capacity of the city's largest employer, the General Motors Corporation (GM). In 1970, GM employed an estimated 80,000 workers at Flint area automotive plants. By 2000, GM and affiliated industries employed less than 16, 000 area workers. As manufacturing jobs left the area, Flint's population declined $36.5 \%$ from 196,940 in 1970 to 124,943 in 2000 (U.S. Census 2001). Flint's population declined another $18 \%$ to 102,434 between 2000 and 2010 (U.S. Census 2011). Accompanying this population decline, Flint has consistently ranked as one of the most dangerous cities in the USA based on Federal Bureau of Investigation crime statistics (Morgan et al. 2014). These characteristics make Genesee County a well-suited location in which to assess attitudes toward the police as past researchers have illustrated the association between neighborhood crime rates and attitude toward police (Lai and Zhao 2010; Weitzer and Tuch 2005). In addition to the City of Flint, Genesee County contains suburban and rural areas, where $53 \%$ of the survey participants included in these analyses resided.

The survey sample was developed based on randomly selected records across all residential Census Tracts from address lists provided by the US Post Office. Telephone landline numbers were merged with these records, when available, based on data from Marketing Systems Group. The data collection agency subcontracted with a professional printing/ mailing company and mailed prenotification letters informing residents about the Community Survey. The survey could be completed in three ways: as a mailed hardcopy (send in a SelfAddressed Stamped Envelope), a Qualtrics ${ }^{\mathrm{TM}}$ survey on the Internet, and as a Computer Aided Telephone Interview. The letter noted that the survey provided multiple options for completion and contained a link to the on-line survey website.

Two weeks after the prenotification letter mailing, the data collection agency began telephone contact for households with appended phone numbers and mailed survey packets to address-only households. Households were again given the choice of survey method for completion. Reminder letters were sent to nonresponders in order to increase response rates and obtain target completes per Census Tract. The health department also featured a link to the on-line survey from its homepage. The data collection agency managed call attempts in a manner comparable to the standard Behavioral Risk Factor Surveillance System protocol (i.e., up to 10 attempts, screening for eligible households, assign final disposition codes). The response rate was $25 \%$. The most frequent method of survey completion was returning hardcopy surveys in a self-addressed stamped envelope (SASE, $n=861,72.5 \%$ ), followed by the on-line survey ( $n=257,21.7 \%)$, landline telephone survey $(n=$ $55,4.6 \%$ ), and 14 hardcopy surveys (1.2\%) distributed and collected by Community Based Organization (CBO) partners. Maintaining cases with complete data on the study measures resulted in an analytical sample of $N=1069$.

\section{Measures}

Survey respondents answered five questions about their attitudes toward the police on a five-point (Strongly Agree [5] to Strongly Disagree [1]) scale. These included the root phrase, 
"The police in my neighborhood...," followed by the branch phrases "treat people with respect," "take time to listen to people," "explain their decisions to people they deal with," and "can be trusted." The individual items were then combined to form the procedural justice scale (Cronbach's alpha $=.935)$, where higher values indicate stronger perceptions of procedural justice. These items match similar questions used in the extant literature to tap the procedural justice component of the process-based model (cf. Reisig et al. 2007).

Participants also answered two questions regarding their willingness to contact the police. Specifically, participants were asked, "How likely would you be to contact the police to report a crime if one occurred?" and "How likely would you be to talk with a police officer for any other reason?" Participants completed the same five-point scale as for the attitudes toward police questions, where higher values indicate an increased willingness to initiate contact with the police. As noted, researchers argue that citizens who perceive the function and power of the police to be legitimate are also more likely to obey and rely on the police (Sunshine and Tyler 2003). Consequently, these two items were combined to represent the police legitimacy portion of the process-based model of policing.

Past researchers have noted the methodological and theoretical value to employing both individual and global attitudinal measures of perceptions of the police (Lai and Zhao 2010; Reisig et al. 2007). Consequently, we constructed a global attitude toward the police measure composed of the four items tapping procedural justice and the two items tapping police legitimacy. The six items all loaded on a similar factor and showed strong internal consistency (Cronbach's alpha $=.866$ ). Higher values on the global measure of attitude toward the police represent a more positive overall perspective of the police.

Employing Differential K theory, Figueredo et al. (2005) developed the Arizona Life History Battery (ALHB) based on analysis of a large national dataset from the Midlife in the US (MIDUS) study. The ALHB is a composite of developmental experiences, proclivity toward risk-taking, and social support, which systematically cluster in life history variation. We employed the 20-item Arizona Life History Battery Short Form (Mini-K; Figueredo et al. 2006). This is not a traditional short-form measure of one psychological construct, but rather a brief proxy for an entire battery of convergent life history scales (Figueredo et al. 2014). Different subsets of items all assess the same underlying latent common factor of a slow human life history. The Mini-K correlates strongly with the full 199-item Arizona Life History Battery (Dunkel and Decker 2010; Figueredo et al. 2014), predicts theoretically convergent indicators of a slow life history strategy, as assessed with standard (longer) instruments (Gladden et al. 2008; Figueredo et al. 2006; Figueredo and Wolf 2009; Sefcek, and Figueredo 2010), and demonstrates construct and criterion-related validity (Figueredo et al. 2014; Olderbak et al. 2014; see also Figueredo et al. 2013). Respondents provided their level of agreement on a 7-point scale (Disagree strongly [-3] to Agree Strongly [+3]) to questions such as "I am often in social contact with my blood relatives," "I avoid taking risks," and "I would rather have one than several sexual relationships at a time." The items were then combined to form the life history strategy scale (Cronbach's alpha $=.814$ ) where the higher the score on the Mini-K, the slower a person's life history strategy.

Four demographic items were used as control variables in the analyses. First, respondents' age was included and was measured continuously in years. Second, the sex of respondents was coded dichotomously where $0=$ female and $1=$ male. Third, race was also coded dichotomously where $0=$ White or European American and 1=Black or African American (note: less than $2 \%$ of the sample indicated another race other than Black or White). Finally, we also controlled for the influence of educational attainment coded continuously in years, where higher values indicate a greater number of years of education completed. The descriptive statistics for all of the study variables are displayed in Table 2 .

\section{Analyses}

In order to test the study hypotheses, we conducted a series of interrelated analytical steps. First, we assessed the zero-order associations among the study variables. Second, we constructed a series of path models to test our hypotheses. We included age, sex, race, and education as exogenous predictors of each of the other constructs. The Mini-K (" $K$ ") scores were included to predict procedural justice and police legitimacy, and we allowed procedural justice to directly predict police legitimacy enabling a potential-mediated path from life history scores (" $K$ "). The initial model was created with all possible predictive paths freed. Nonsignificant paths were trimmed from the model based on descending $p$ values. A final parsimonious model was constructed with remaining paths that were statistically significant (i.e., $p<.05$ ). Finally, these steps were repeated using the global attitude toward police measure in place of the two constituent scales (i.e., procedural justice and police legitimacy). We also conducted post hoc analyses examining whether the association between life history and police outcome measures could be explained by other factors.

\section{Results}

The first step in our analysis was to assess the zero-order associations among the study variables. These results are displayed in Table 3. As illustrated, two of the control variables are associated with the life history strategy measure, and three are associated with the procedural justice, the police legitimacy, and the global attitude scales. Consequently, we 
Table 2 Descriptive statistics for all study variables $(N=1069)$

ALHB (Mini-K) (M, SD)

Procedural Justice (M, SD)

Police Legitimacy (M, SD)

Global Police Attitude (M, SD)

Age (y, SD)

Race

$\begin{array}{ll}\text { White (1) } & 76 \% \\ \text { Black (2) } & 24 \%\end{array}$

Sex

$\begin{array}{ll}\text { Female (1) } & 73 \% \\ \text { Male (2) } & 27 \%\end{array}$

Education

$53 \pm 15$

$76 \%$

$27 \%$
$4.03 \pm 0.44$

$3.60 \pm 0.91$

$4.35 \pm 0.83$

$3.84 \pm 0.76$

$\begin{array}{ll}\text { Less than High School } & 5 \% \\ \text { High School } & 20 \% \\ \text { Technical school } & 5 \% \\ \text { Some college } & 27 \% \\ \text { Associate's } & 12 \% \\ \text { Bachelor's } & 17 \% \\ \text { Master's or higher } & 14 \%\end{array}$

$M$ mean, $y$ years, $S D$ standard deviation, $A L H B$ Arizona life history battery

maintain inclusion of the control variables in the path models. The second step in the analysis included the use of a series of path models to directly assess our hypotheses. The results of these analyses are displayed in Figs. 1 and 2. Examination of Fig. 1 illustrates that as expected, age, sex, and educational attainment covaried with life history. More specifically, older individuals, women, and those with higher educational attainment indicated slower life history. Once these factors were controlled for, however, race did not have a unique association with life history. Continued examination of Fig. 1 indicates that slower life history uniquely predicted greater perceptions of both procedural justice and police legitimacy. The relationship between slower life history and greater perceptions of procedural justice was the second strongest relationship identified in the model, following the anticipated highly shared variance between procedural justice and police legitimacy. Procedural justice mediated the relationship between life history and police legitimacy. In addition to the significant association between life history strategy and perceptions of procedural justice, higher educational attainment, White race, and older age also uniquely predicted perceptions of procedural justice. In sum, our predictors accounted for $18 \%$ of the variance in procedural justice and $17 \%$ of the variance in police legitimacy.

The model predicting global attitude toward the police (see Fig. 2) uses the same framework to examine the entire set of police-related items as a whole. The pattern of prediction for life history $(K)$ is identical to that in the previous model. Life history $(K)$ was the strongest predictor of global attitude toward the police, explaining $10 \%$ of the variance. Higher levels of education, older age, and White race also predicted more positive global attitudes toward the police, accounting for an additional $9 \%$ of the variance (19\% in total).

In post hoc analyses, we examined whether the association between life history and police outcome measures could be explained by proximity to criminal activity or experiences of discrimination. We ran partial correlations controlling for whether or not respondents had a friend or relative in prison in the past 5 years (binary yes/no), the total number of individuals known in prison in the past 5 years (continuous), and demographic covariates (age, sex, race, education). All associations remained significant: procedural justice, $r(1016)=.296, p<.0001$; police legitimacy, $r(1016)=.181$, $p<.0001$; and global attitude toward police, $r(1016)=.306$, $p<.0001$. We then replicated these partial correlations, adding a five-item measure (Cronbach's alpha $=.832$ ) of experiences of discrimination in the past 12 months (from The Everyday Discrimination Scale; Williams et al. 1997). Again, all associations remained significant: procedural justice, $r(1015)=.275, p<.0001$; police legitimacy, $r(1015)=.164$, $p<.0001$; and global attitude toward police, $r(1015)=.284$, $p<.0001$.

Table 3 Zero-order correlations among the study variables

(1) $\mathrm{K}$

(2) Procedural justice

(3) Police legitimacy

(4) Global police attitude

(5) Age

(6) Male

(7) Black

(8) Education
(1)

(2)

$.307^{* *}$
$.215^{* *}$
$.323^{* *}$
.011
$-.184^{* *}$
.028
$.188^{* *}$

(3)

(4)

(5)

(6)

(7)

${ }^{*} p<.05$ (two-tailed test); ${ }^{*} p<.01$ (two-tailed test); male: $0=$ no, $1=$ es; Black: $0=$ no, $1=$ yes. The Global police attitude scale (4) is a combination of the procedural justice (2) and police legitimacy (3) items 


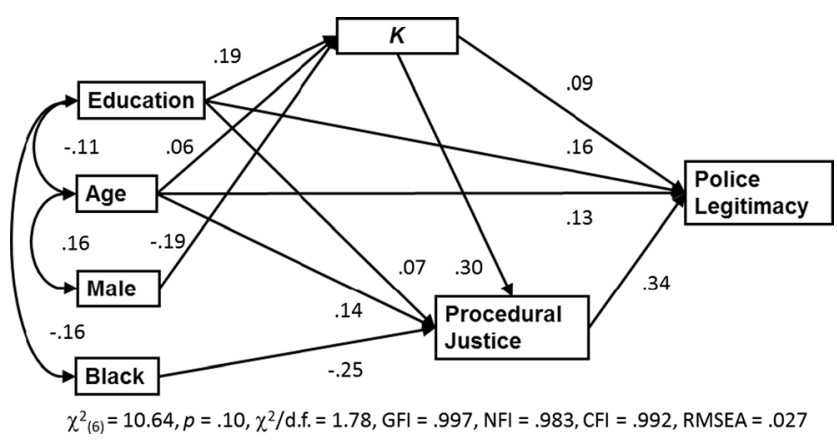

Fig. 1 Standardized regression coefficients in parsimonious path model predicting procedural justice and police legitimacy

\section{Discussion}

Attitudes toward the police are of increasing concern to scholars and practitioners, and this concern is especially high in crime-prone areas. Most studies examining individual differences in police attitudes examine differences based on basic demographic factors. However, there is a lack of consensus in terms of which demographic factors account for the greatest amount of variance in attitudes toward the police. Some researchers have noted that this inconsistency could be due to the multitude of theories that are applied to assessments of perceptions of the police or to the lack of theoretical guidance. Using these observations in the extant literature as a springboard, we applied a component of evolutionary biology, LHT. In this study, we demonstrated that an individual's life history has a strong influence on perceptions of procedural justice and police legitimacy, as measured by intentions to contact the police. Life history was related to demographic factors, but these characteristics did not account for the relationship between life history and police attitudes. Overall, our results indicate that slower life history is associated with greater perceptions of procedural justice, increased views of police legitimacy, and an overall positive attitude toward the police. Given the evolutionary biological roots of LHT, these findings indicate that a biosocial process may underpin the development and expression of perceptions of the police (Beaver 2009). Furthermore, the findings speak to the potentially critical role that police can play within a social network of group members.

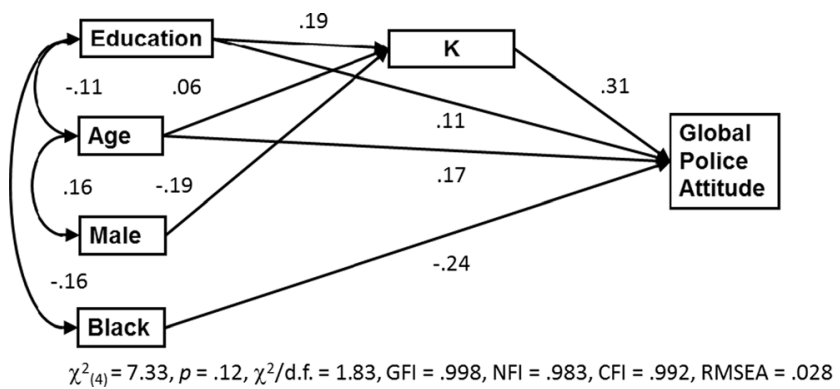

Fig. 2 Standardized regression coefficients in parsimonious path model predicting global police attitude
The results of the current study provide a unique contribution to the theoretical literature on perceptions of the police and illustrate the need recognized by other researchers that citizens' attitudes toward police are more nuanced than provided in past examinations of the dynamic between police and public views of the police (e.g., Wolfe 2011). Our results echo Wolfe's (2011, p. 72) assertion that "individuals do not evaluate the police as blank slates." Individual variance in life history was a strong predictor of attitudes toward the police in multiple models even after controlling for the effect of numerous important demographic and behavioral characteristics. Given that variance in life history is partially impacted by individual characteristics (e.g., genetic factors), our findings provide further support for this assertion.

Our findings also highlight the importance of socioenvironmental conditions in the development and expression of perceptions of the police. Recall that individual variation in life history is influenced, in addition to genetic factors, by the stability and predictability of an organism's environment. Consequently, given the illustration of the association between life history and perceptions of the police our findings call for policy which can impact the stability of environmental conditions as a method to enhance perceptions of the police. In other words, laying the responsibility of increasing attitudes toward police solely on law enforcement agencies may be an unfair and unfruitful exercise. Enhancing the perceptions of police may require the cooperation of numerous social agencies directed at the stabilization of environments. This stabilization could help to decrease the perception of police as a potential rival within the social network system and increase the perception of the police as maintainers of stability and social order. Future research would do well to examine which socioenvironmental conditions influence life history in such ways as to best enhance public perception of the police.

In addition to the finding that life history predicted attitudes toward the police, our assessment added to the literature illustrating consistent differences in perceptions between racial groups. Although the effect of race was not as strong as the effect of life history, our examination illustrated that African Americans were more likely to have negative views of the police. Although this association was significant, race was not associated with life history once educational attainment, age, and sex were accounted for in the analysis. Older individuals, women, and those with higher educational attainment indicated slower life history. At the time of data collection, Flint was characterized by a massive economic outmigration. It is possible that those remaining in the city are more similar to each other than racial groups in other metropolitan areas. Matching for educational attainment also reduces group differences. Consequently, our results indicate that factors beyond individual variation in life history that are associated with race are important to understanding variation in attitudes toward the police. We encourage future research to examine 
this relationship while also controlling for the effects of variance in life history. Beaver et al. (2013b) showed that racial disparities in American male incarceration rates were completely accounted for after including covariates for selfreported lifetime violence and verbal IQ scores. If these predictors were available, they would likely contribute to the variance in our analyses. However, we would not expect them to fully account for the central findings, as meta-analysis indicates that life history and intelligence $(g)$ are orthogonal (Woodley 2011).

Our confidence in our conclusions is augmented by the test of our hypotheses in a large, demographically representative community sample. The survey participants live in a community beset by very high rates of violent crimes and thus considerable police activity. Although the current study employed similar methodologies to those in past studies (i.e., phone surveys; e.g., Reisig et al. 2007), the sample utilized in the analyses matches few in the extant literature in terms of the inclusion of participants from a high crime area. Past researchers have employed high school and college samples (Goudriaan and Nieuwbeerta 2007; Wolfe 2011), national samples (Gibson et al. 2009; Reisig et al. 2007), city-wide registered voters (Sunshine and Tyler 2003), serious juvenile offenders (Lee et al. 2010), among others. The extent to which measures of perceptions of the police in these samples are valid may be questionable due to varied frequency and quality of police-citizen interactions. By employing a community representative sample, which includes a high crime urban area, the current study incorporated respondents who reside in areas of high police-citizen interaction. Therefore, the respondents' perceptions of the police are likely derived from proximal relationships with police and are less likely to be derived from distal sources such as the media. This recognition adds to the reliability of the results of our analysis. We do note that those with less than a high school education are undersampled with respect to their population proportion (as is typical of community surveys). These individuals are likely to have a fast life history and less favorable attitudes toward the police. Thus, our sample may be restricted in range in a way that would weaken the predicted relationships.

Although the use of a community sample strengthens the confidence in the analyses, our findings should be tempered by three main limitations. First, due to time constraints and concerns about respondent dropout, our measures of perceptions of the police are not as expansive as some employed in the extant literature. However, the scales used in the current study matched theoretical expectations and past empirical analyses in their association with key demographic variables. Nonetheless, future research examining the influence of life history on attitudes toward police may benefit from a more comprehensive measure.

Second, although the sample is a strong sample by which to examine the development and expression of attitudes toward the police, it is derived from a specific location, the characteristics of which may not be representative of other areas. To the extent that the socioenvironmental conditions found in Genesee County, MI differ from other areas of the world, generalizations of our results should be tempered accordingly. For example, discussions with community members reveal that the understaffing of the police force is the primary community concern. At the time of data collection, there was only one community liaison officer for the entire City of Flint. Residents of other areas across the world will likely have other concerns, such as police corruption. The general level of police corruption may differ from other areas, though this would not explain the demonstrated relationships based on individual variation.

Our aim is to demonstrate the relationship between life history and cooperation with the police, rather than systematically identify all of the factors affecting attitudes toward the police. Perceptions of police competency, effectiveness, and corruption would also likely predict cooperation with the police. As we did not assess individuals' actual experiences with police, this would increase unexplained variability (noise) and make it more difficult to find the predicted relationships. We note that some of the constructs included in our arguments are not directly assessed, such as perceptions of the social functions of police, and the relationships with these constructs will need to be confirmed by future research. Biosocial criminologists have noted the methodological problems that can arise when ignoring the influence of genetic factors in criminological research (Barnes et al. 2014a). Heritable genotypic variation would likely explain some of the variance and interrelationship in our model, as life history strategies are partially heritable (Figueredo and Rushton 2009; Figueredo et al. 2004; Heath and Hadley 1998; Minkov and Bond 2015). However, part of the value of LHT is the explicit recognition that developmental environments shape phenotypes (beyond the influence of genetic factors). Thus, we believe that our findings cannot be reduced solely to genetic factors, as has been demonstrated in previous similar work (Kruger et al. 2008). Future research utilizing twins or other siblings for comparisons, and direct assessment of genetic and epigenetic factors will help clarify this issue.

With these limitations in mind, this study provides considerable empirical support for our specific hypotheses and also suggestive evidence from the broader theory from which they are derived. If true, this relationship between life history variation and social patterns would have broad and consequential implications. Environments fostering faster human life histories may also exhibit qualitatively different social infrastructures. Individual perceptions may accurately track the social reality; in fact, it would be adaptive for them to do so. Overall, this project illustrates how LHT promotes understating in application to real-world social issues, in addition to the traditional academic domains of criminology and evolutionary psychology. 


\section{References}

Alexander, R. D. (1979). Darwinism and human affairs. Seattle: University of Washington Press.

Anderson, E. (1999). Code of the street: decency, violence, and the moral life of the inner city. New York: W.W. Norton \& Company.

Baker, T., Pelfrey, W. V., Bedard, L. E., Dhungana, K., Gertz, M., \& Golden, K. (2014). Female inmates' procedural justice perceptions of the police and courts: Is there a spill-over of police effects? Criminal Justice and Behavior, 41, 144-162.

Barnes, J. C., Boutwell, B. B., Beaver, K. M., Gibson, C. L., \& Wright, J. P. (2014a). On the consequences of ignoring genetic influences in criminological research. Journal of Criminal Justice, 42, 471-482.

Barnes, J. C., Wright, J. P., Boutwell, B. B., Schwartz, J. A., Connolly, E. J., Nedelec, J. L., \& Beaver, K. M. (2014b). Demonstrating the validity of twin research in criminology. Criminology, 52, 588-626.

Barton, R. A., \& Capellini, I. (2011). Maternal investment, life histories, and the costs of brain growth in mammals. Proceedings of the National Academy of Sciences, 108, 6169-6174.

Beaver, K. M. (2009). Biosocial criminology: a primer. Dubuque: Kendall Hunt Publishing Company.

Beaver, K. M., DeLisi, M., Wright, J. P., Boutwell, B. B., Barnes, J. C., \& Vaughn, M. G. (2013a). No evidence of racial discrimination in criminal justice processing: results from the national longitudinal study of adolescent health. Personality and Individual Differences, $55,29-34$.

Beaver, K. M., Schwartz, J. A., Nedelec, J. L., Connolly, E. J., Boutwell, B. B., \& Barnes, J. C. (2013b). Intelligence is associated with criminal justice processing: arrest through incarceration. Intelligence, 41 , 277-288.

Belsky, J., Steinberg, L., \& Draper, P. (1991). Childhood experience, interpersonal development, and reproductive strategy: an evolutionary theory of socialization. Child Development, 62, 647-670.

Boutwell, B. B., Barnes, J. C., Deaton, R., \& Beaver, K. M. (2013). On the evolutionary origins of life-course persistent offending: a theoretical scaffold for Moffitt's developmental taxonomy. Journal of Theoretical Biology, 322, 72-80.

Brown, B., \& Benedict, W. R. (2002). Perceptions of the police: Past findings, methodological issues, conceptual issues and policy implications. Policing, 25, 543-580.

Chisholm, J. S. (1999). Death, hope and sex: steps to an evolutionary ecology of mind and morality. Cambridge: Cambridge University Press.

Cole, L. C. (1954). The population consequences of life history phenomena. Quarterly Review of Biology, 29, 103-137.

Comings, D. E., Muhleman, D., Johnson, J. P., \& MacMurray, J. P. (2002). Parent-daughter transmission of the androgen receptor gene as an explanation of the effect of father absence on age of menarche. Child Development, 73, 1046-1051.

Cosmides, L., \& Tooby, J. (1994). Origins of domain specificity: The evolution of functional organization. In L. A. Hirschfeld \& S. A. Gelman (Eds.), Mapping the mind: domain specificity in cognition and culture (pp. 85-116). Cambridge: Cambridge University Press.

Dobzhansky, T. (1950). Evolution in the tropics. American Scientist, 38, 209-221.

Dunkel, C. S. (2012). Do self-report measures of life history strategy exhibit the hypothesized differences between blacks and whites predicted by differential $K$ theory? Personality and Individual Differences, 52, 759-761.

Dunkel, C. S., \& Decker, M. (2010). Convergent validity of measures of life-history strategy. Personality and Individual Differences, 48, 681-684.

Ellis, L. (1988). Criminal behavior and $\mathrm{r} / \mathrm{K}$ selection: an extension of gene-based evolutionary theory. Personality and Individual Differences, 9, 697-708.
Ellis, B. J., McFadyen-Ketchum, S., Dodge, K. A., Pettit, G. S., \& Bates, J. S. (1999). Quality of early family relationships and individual differences in the timing of pubertal maturation in girls: a longitudinal test of an evolutionary model. Journal of Personality and Social Psychology, 77, 387-401.

Figueredo, A. J., \& Rushton, J. P. (2009). Evidence for shared genetic dominance between the general factor of personality, mental and physical health, and life history traits. Twin Research and Human Genetics, 12, 555-563.

Figueredo, A. J., \& Wolf, P. S. A. (2009). Assortative pairing and life history strategy: a cross-cultural study. Human Nature, 20, 317-330.

Figueredo, A. J., Vásquez, G., Brumbach, B. H., \& Schneider, S. M. R. (2004). The heritability of life history strategy: the K-factor, covitality, and personality. Social Biology, 51, 121-143.

Figueredo, A. J., Vásquez, G., Brumbach, B. H., Sefcek, J. A., Kirsner, B. R., \& Jacobs, W. J. (2005). The K-Factor: individual differences in life history strategy. Personality and Individual Differences, 39, $1349-1360$.

Figueredo, A. J., Vásquez, G., Brumbach, B. H., Schneider, S. M., Sefcek, J. A., Tal, I. R., Hill, D., Wenner, C. J., \& Jacobs, W. J. (2006). Consilience and life history theory: from genes to brain to reproductive strategy. Developmental Review, 26, 243-275.

Figueredo, A. J., Cabeza de Baca, T., \& Woodley, M. A. (2013). The measurement of human life history strategy. Personality and Individual Differences, 55, 251-255.

Figueredo, A. J., Wolf, P. S. A., Olderbak, S. G., Gladden, P. R., Wenner, C., Hill, D., Andrzejczak, D. J., Lichota, J. W., Sisco, M. M., Jacobs, J., Hohman, Z. J., Sefcek, J. A., MacDonald, K., Howrigan, D., Kruger, D. J., \& Rushton, J. P. (2014). The psychometric assessment of human life history strategy: a meta-analytic construct validation. Evolutionary Behavioral Sciences, 8, 148-185.

Fisher, R. A. (1958). The genetical theory of natural selection. (2nd ed.) NY: Dover.

Gadgil, M., \& Bossert, W. H. (1970). Life historical consequences of natural selection. American Naturalist, 104, 1-24.

Gau, J. M., Corsaro, N., Stewart, E. A., \& Brunson, R. K. (2012). Examining macro-level impacts on procedural justice and police legitimacy. Journal of Criminal Justice, 40, 333-343.

Gibson, C. L., Walker, S., Jennings, W. G., Miller, J. M., \& Leffler, M. A. (2009). The impact of traffic stops on calling the police for help. Criminal Justice Policy Review, 21, 139-159.

Gladden, P. R., Figueredo, A. J., \& Jacobs, W. J. (2008). Life history strategy, psychopathic attitudes, personality, and general intelligence. Personality and Individual Differences, 46, 270-275.

Goudriaan, H., \& Nieuwbeerta, P. (2007). Contextual determinants of juveniles' willingness to report crimes. A vignette experiment. Journal of Experimental Criminology, 3, 89-111.

Hamilton, W. D. (1966). The moulding of senescence by natural selection. Journal of Theoretical Biology, 21, 12-45.

Heath, K., \& Hadley, C. (1998). Dichotomous male reproductive strategies in a polygynous human society: mating versus parental effort. Current Anthropology, 39, 369-374.

Hill, E. M., Ross, L. T., \& Low, B. S. (1997). The role of future unpredictability in human risk-taking. Human Nature, 8, 287-325.

Hrdy, S. B. (2009). Mothers and others: the evolutionary origins of mutual understanding. Cambridge: Harvard University Press.

Kaplan, H. (1997). The evolution of the human life course. In K. W. Wachter \& C. E. Finch (Eds.), Between Zeus and the salmon: the biodemography of longevity (pp. 175-211). Washington, DC: National Academy Press.

Kaplan, H. S., \& Gangestad, S. W. (2005). Life history theory and evolutionary psychology. In D. M. Buss (Ed.), The handbook of evolutionary psychology (pp. 68-95). Hoboken: Wiley.

Kim, K., Smith, P. K., \& Palermiti, A. L. (1997). Conflict in childhood and reproductive development. Evolution and Human Behavior, 18, 109-142. 
Kruger, D. J., \& Nesse, R. M. (2006). An evolutionary life-history framework for understanding sex differences in human mortality rates. Human Nature, 17, 74-97.

Kruger, D. J., Reischl, T. M., \& Zimmerman, M. A. (2008). Time perspective as a mechanism for functional developmental adaptation. Journal of Social, Evolutionary, and Cultural Psychology, 2, 1-22.

Lai, Y. L., \& Zhao, J. S. (2010). The impact of race/ethnicity, neighborhood context, and police/citizen interaction on residents' attitudes toward the police. Journal of Criminal Justice, 38, 685-692.

Lee, R. D. (1997). Intergenerational relations and the elderly. In K. W. Wachter \& C. E. Finch (Eds.), Between Zeus and the salmon: the biodemography of longevity (pp. 212-234). Washington, DC: National Academy Press.

Lee, J. M., Steinberg, L., Piquero, A. R. (2010). Ethnic identity and attitudes toward the police among African American juvenile offenders. Journal of Criminal Justice, 38, 781-789.

Low, B. (1998). The evolution of human life histories. In C. Crawford \& D. Krebs (Eds.), Handbook of evolutionary psychology: issues, ideas, and applications (pp. 131-161). Mahwah: Lawrence Erlbaum Associates.

MacArthur, R., \& Wilson, E. O. (1967). The theory of island biogeography. Princeton: Princeton University Press.

Minkov, M., \& Bond, M. H. (2015). Genetic polymorphisms predict national differences in life history strategy and time orientation. Personality and Individual Differences, 76, 204-215.

Moffitt, T. E. (2005). Genetic and environmental influences on antisocial behaviors: evidence from behavioral-genetic research. Advances in Genetics, 55, 41-104.

Moffitt, T. E., Ross, S., \& Raine, A. (2011). Crime and biology. In J. Q. Wilson \& J. Petersilia (Eds.), Crime and public policy (pp. 53-87). New York: Oxford University Press.

Morgan, S., Morgan, K. O., \& Boba Santos, R. (2014). City crime rankings 2014. Washington, DC: CQ Press.

Nedelec, J. L., \& Beaver, K. M. (2012). The association between sexual behavior and antisocial behavior: Insights from an evolutionary informed analysis. Journal of Contemporary Criminal Justice, 28, 329-345.

Olderbak, S., Gladden, P., Wolf, P. S. A., \& Figueredo, A. J. (2014). Comparison of life history strategy measures. Personality and Individual Differences, 58, 82-88.

Pianka, E. R. (1970). On r- and K-selection. American Naturalist, 104, 592-596.

Posick, C., Rocque, M., \& McDevitt, J. (2013). One scale fits all? Assessing racial differences in the measurement of attitudes toward the police. Race and Justice, 3, 190-209.

Quinlan, R. J. (2007). Human parental effort and environmental risk. Proceedings of the Royal Society-Series B, 274, 121-125.

Raine, A. (2002). Biosocial studies of antisocial and violent behavior in children and adults: a review. Journal of Abnormal Child Psychology, 30, 311-326.

Reisig, M. D., Bratton, J., \& Gertz, M. G. (2007). The construct validity and refinement of process-based policing measures. Criminal Justice and Behavior, 34, 1005-1028.

Roff, D. A. (1992). The evolution of life histories: theory and analysis. New York: Chapman \& Hall.

Rushton, J. P. (1985). Differential K theory: the sociobiology of individual and group differences. Personality and Individual Differences, 6 , 441-452.

Schmalhausen, I. I. (1949). Factors of evolution. Philadelphia: Blakiston.

Sefcek, J. A., \& Figueredo, A. J. (2010). A life-history model of human fitness indicators. Biodemography and Social Biology, 56, 41-66.
Stearns, S. C. (1992). The evolution of life histories. Oxford: Oxford University Press.

Sunshine, J., \& Tyler, T. R. (2003). The role of procedural justice and legitimacy in shaping public support for policing. Law \& Society Review, 37, 513-548.

Trivers, R. (1972). Parental investment and sexual selection. In B. Campbell (Ed.), Sexual selection and the descent of man (pp. 136179). Chicago: Aldine-Atherton.

Tuch, S. A., \& Weitzer, R. (1997). Trends: racial differences in attitudes toward the police. The Public Opinion Quarterly, 61, 642-663.

Tyler, T. R. (1997). The psychology of legitimacy: a relational perspective on voluntary deference to authorities. Personality and Social Psychology Review, 1, 323-345.

Tyler, T. R. (2004). Enhancing police legitimacy. The Annals of the American Academy of Political and Social Science, 593, 84-99.

Tyler, T. R. (2005). Policing in black and white: ethnic group differences in trust and confidence in the police. Police Quarterly, 8, 322-342.

Tyler, T. R. (2006). Why people obey the law. Princeton: Princeton University Press.

Tyler, T. R., \& Wakslak, C. L. (2004). Profiling and police legitimacy: procedural justice, attributions of motive, and acceptance of police authority. Criminology, 42, 253-282.

Tyler, T. R., \& Fagan, J. (2008). Legitimacy and cooperation: why do people help the police fight crime in their communities? Ohio State Journal of Criminal Law, 6, 231-275.

U.S. Census Bureau (2001). Census 2000 summary file 1 (SF 1) 100percent data. Washington, DC: Author.

U.S. Census Bureau (2011). Census 2010 summary file 1 (SF 1) 100percent data. Washington, DC: Author.

Walsh, A., \& Beaver, K. M. (2009). Introduction to biosocial criminology. In A. Walsh \& K. M. Beaver (Eds.), Biosocial criminology: new directions in theory and research (pp. 7-28). New York, NY: Routledge.

Weinrich, J. D. (1977). Human sociobiology: pair-bonding and resource predictability (effects of social class and race). Behavioral Ecology and Sociobiology, 2, 91-118.

Weitzer, R. J., \& Tuch, S. A. (2005). Racially biased policing: determinants of citizen perceptions. Social Forces, 83, 1009-1030.

Williams, D. R., Yu, Y., Jackson, J. S., \& Anderson, N. B. (1997). Racial differences in physical and mental health: socioeconomic status, stress, and discrimination. Journal of Health Psychology, 2, 335351.

Wilson, M., \& Daly, M. (1992). The man who mistook his wife for chattel. In J. H. Barkow, L. Cosmides, \& J. Tooby (Eds.), The adapted mind (pp. 289-322). Oxford: Oxford University Press.

Wilson, M., \& Daly, M. (1997). Life expectancy, economic inequality, homicide, and reproductive timing in Chicago neighbourhoods. British Medical Journal, 314, 1271-1274.

Wolfe, S. E. (2011). The effect of low self-control on perceived police legitimacy. Journal of Criminal Justice, 39, 67-74.

Woodley, M. A. (2011). The cognitive differentiation-integration effort hypothesis: a synthesis between the fitness indicator and life history models of human intelligence. Review of General Psychology, 15, 228-245.

Wright, J. P., Barnes, J. C., Boutwell, B. B., Schwartz, J. A., Connolly, E. J., Nedelec, J. L., \& Beaver, K. M. (2015). Mathematical proof is not minutiae and irreducible complexity is not a theory: a final response to Burt and Simons and a call to criminologists. Criminology, 53, $113-120$. 